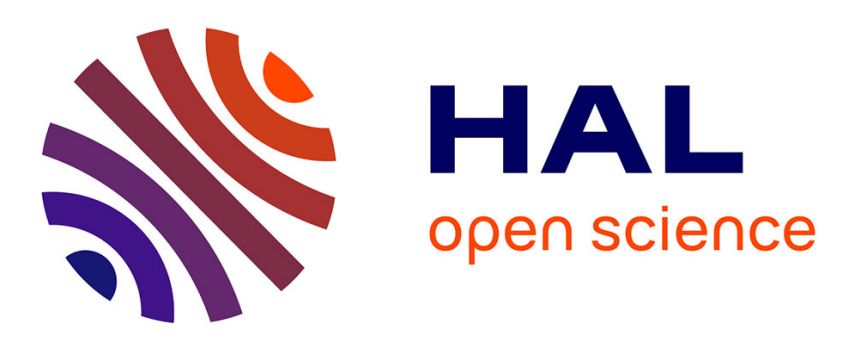

\title{
Solvothermal Synthesis of Oxamate-Based Helicate: Temperature Dependence of the Hydrogen Bond Structuring in the Solid
}

\author{
Laurent Lisnard, Lise-Marie Chamoreau, Yanling Li, Yves Journaux
}

\section{To cite this version:}

Laurent Lisnard, Lise-Marie Chamoreau, Yanling Li, Yves Journaux. Solvothermal Synthesis of Oxamate-Based Helicate: Temperature Dependence of the Hydrogen Bond Structuring in the Solid. Crystal Growth \& Design, 2012, 12 (10), pp.4955-4962. 10.1021/cg300877r . hal-02326706

\section{HAL Id: hal-02326706 https://hal.science/hal-02326706}

Submitted on 30 Oct 2019

HAL is a multi-disciplinary open access archive for the deposit and dissemination of scientific research documents, whether they are published or not. The documents may come from teaching and research institutions in France or abroad, or from public or private research centers.
L'archive ouverte pluridisciplinaire $\mathbf{H A L}$, est destinée au dépôt et à la diffusion de documents scientifiques de niveau recherche, publiés ou non, émanant des établissements d'enseignement et de recherche français ou étrangers, des laboratoires publics ou privés. 


\section{Solvothermal synthesis of oxamate-based}

\section{helicate: temperature dependence of the}

\section{hydrogen-bond-structuring in the solid.}

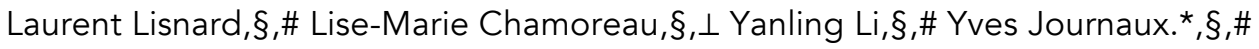

$\S$. Institut Parisien de Chimie Moléculaire, UPMC Univ Paris 06, Paris, 75005, France.

\#. CNRS, Institut Parisien de Chimie Moléculaire, UMR 7201, Paris, 75005, France.

. Centre de résolution structurale, Institut Parisien de Chimie Moléculaire, Paris, 75005, France.

yves.journaux@upmc.fr

CORRESPONDING AUTHOR. Phone: +33 1442755 62; Fax: +33144273841.

ABSTRACT. Solvothermal synthesis has been successfully tested as a new synthetic method towards the formation of oxamate-based coordination compounds. The reaction of 1,3benzenedioxamic acid $\left(\mathrm{H}_{4} \mathrm{mpba}\right)$ with divalent metal ions has afforded the dinuclear compounds $\mathrm{TBA}_{2}\left[\mathrm{Co}_{2}\left(\mathrm{H}_{2} \mathrm{mpba}\right)_{3}\right] .2 \mathrm{DMF} .5 \mathrm{H}_{2} \mathrm{O}$

(1a), $\quad\left(\mathrm{HNEt}_{3}\right)_{2}\left[\mathrm{Co}_{2}\left(\mathrm{H}_{2} \mathrm{mpba}\right)_{3}\right] \cdot 6 \mathrm{DMF} \cdot 5 \mathrm{H}_{2} \mathrm{O}$

$\mathrm{TBA}_{2}\left[\mathrm{Ni}_{2}\left(\mathrm{H}_{2} \mathrm{mpba}\right)_{3}\right] .2 \mathrm{DMF} .2 .5 \mathrm{H}_{2} \mathrm{O}$ (2) and $\left(\mathrm{HNEt}_{3}\right)_{2}\left[\mathrm{Co}_{2}\left(\mathrm{H}_{2} \mathrm{mpba}\right)_{3}\right]$ (3). Although the 3:2 ligand to metal ratio is known for the (mpba) $)^{4-}$ ligand under bench conditions these complexes are the first examples of oxamate-based helicate. Furthermore, crystalographic studies show a temperaturedependent hydrogen bond structuring that leads to racemic or chiral hexagonal 3D networks.

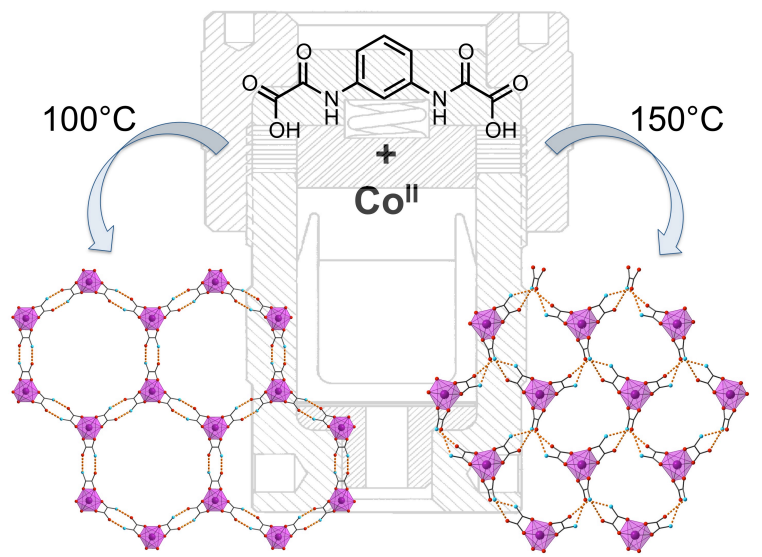




\section{INTRODUCTION}

The synthesis of molecular building blocks that self-assemble or are capable of connexion with another component to form molecular objects or network of defined topology or geometry is one of the major subject in crystal engineering ${ }^{1-2}$ and in supramolecular chemistry ${ }^{3-5}$. The assembly process relies on weak chemical interactions such as $\mathrm{H}$-bond, electrostatic interactions or coordination bonding. However, due to subtle equilibria between these weak interactions there are still a lot of surprises in the outcome and the final product can be quite different from the expected one. These unexpected results often open up new opportunities and contribute greatly to the beauty of synthetic chemistry. Among all the research work on the crystal engineering of nets, the synthesis of metal-organic frameworks has increased exponentially. ${ }^{6}$ The reason for this success is related to the chemical flexibility of these materials owing to the presence of tunable organic and inorganic parts which allows to scale up the system or to introduce new properties. Moreover MOFs have a lot of potential applications in catalysis but also in hydrogen ${ }^{7}$ and $\mathrm{CO}_{2}{ }^{8}$ storage which are two of the most pressing technological social needs. MOFs are also highly interesting for their physical properties such as luminescence ${ }^{9-10}$ or ferroelectricity ${ }^{11}$ and magnestism ${ }^{12}$. Regarding magnetic MOFs, the goal is the obtention of magnets and more precisely porous magnets, so in addition to the control over atom arrangement, the ability of organic ligands to propagate the electronic interaction between the magnetic ions is of paramount importance. At first sight, large porosity seems incompatible with magnetic ordering due to the exponential decrease of the interaction between the magnetic ions with growing metal-metal distances $^{13-14}$ inevitably leading to a dramatic drop in the ordering temperature value when the system is scaled up with longer organic linkers. To tackle this problem, we have designed over the past few years new polytopic oxamate-based ligands able to efficiently transmit electronic interaction across extended aromatic bridges via spin polarization mechanism. Starting from these ligands, we were able to obtain homometallic polynuclear complexes which effectively exhibit relatively strong ferromagnetic interaction in spite of large metal-metal separation ${ }^{15-18}$. When reacted with additional metal ions, some of these complexes give 2D or 3D magnetic MOFs ${ }^{19-21}$ with magnetic ordering in the $6.5 \mathrm{~K}$ to $22.5 \mathrm{~K}$ temperature range. The metal-metal distance through the bridging oxamate ligand is not tunable but with the help of serendipity large octogonal pores have been obtained. ${ }^{21}$ Furthermore these networks are resizable by changing the aromatic parts while retaining a significant interaction. Nevertheless the final geometry of the nets depends on subtle chemical equilibria and to fully exploit this family of ligand we have decided to explore their reactivity in solvothermal conditions. This method imposes strong constraints both in 
pressure and in temperature to the reaction media and allows to work beyond the solvent's boiling point. ${ }^{22}$ Consequently the solubility and the mobility of the reactants are increased and reactions that could not be carried or would not yield crystals under bench conditions become feasible. ${ }^{23}$ This method has convincingly proved its efficiency for the synthesis of multidimensional materials ${ }^{24-}$ ${ }^{25}$ as well as the synthesis of coordination clusters ${ }^{26}$ and represents therefore a convenient tool to investigate polyoxamate's reactivity.

To start our study we have been focusing on the 1,3-benzenedioxamate ligand (Figure 1a) since it is known to promote ferromagnetic exchange between paramagnetic ions through spin polarisation mechanism. ${ }^{15}$ We have thus reacted this ligand with cobalt(II) or nickel(II) salts in DMF varying the temperature of the solvothermal treatment. Reactions carried at $100^{\circ} \mathrm{C}$ in the presence of $\mathrm{TBAOH}$ or $\mathrm{NEt}_{3}$ have yielded the bimetallic compounds $\mathrm{TBA}_{2}\left[\mathrm{Co}_{2}\left(\mathrm{H}_{2} \mathrm{mpba}\right)_{3}\right] .2 \mathrm{DMF} .5 \mathrm{H}_{2} \mathrm{O}$ (1a), $\left(\mathrm{HNEt}_{3}\right)_{2}\left[\mathrm{Co}_{2}\left(\mathrm{H}_{2} \mathrm{mpba}\right)_{3}\right] .6 \mathrm{DMF} .5 \mathrm{H}_{2} \mathrm{O}$ (1) b) and $\mathrm{TBA}_{2}\left[\mathrm{Ni}_{2}\left(\mathrm{H}_{2} \mathrm{mpba}\right)_{3}\right] .2 \mathrm{DMF} .2 .5 \mathrm{H}_{2} \mathrm{O}$ (2) whereas the compound $\left(\mathrm{HNEt}_{3}\right)_{2}\left[\mathrm{Co}_{2}\left(\mathrm{H}_{2} \mathrm{mpba}\right)_{3}\right]$ (3) has been obtained at $150^{\circ} \mathrm{C}$ in the presence of triethylamine. Crystallographic studies reveal that all the complexes adopt a helicate geometry which has never been observed to date in oxamate-based complexes. X-ray diffraction studies also show that the supramolecular hydrogen-bond arrangement of the complexes in the solid is strongly dependent of the reaction temperature: reactions performed at $100^{\circ} \mathrm{C}$ have afforded a racemic hexagonal $3 \mathrm{D}$ structure in contrast with a chiral phase that forms at $150^{\circ} \mathrm{C}$.

\section{EXPERIMENTAL SECTION}

Materials and Methods. All reagents were used as purchased with no further purification. Diethyl N,N'-1,3-benzenedioxamate, $\mathrm{H}_{2} \mathrm{Et}_{2} \mathrm{mpba}$, was prepared according to the literature procedure. ${ }^{27}{ }^{1} \mathrm{H}$ and ${ }^{13} \mathrm{C}$ NMR spectra were collected on a $400 \mathrm{MHz}$ Bruker Avance spectrometer at 298 K. ATR/FT-IR spectra were collected on a Bruker TENSOR 27 equipped with a simple reflexion ATR diamond plate of the Harrick MPV2 series. Magnetic measurements in dc mode were performed on a Quantum Design MPMS SQUID on polycrystalline samples restrained in a plastic film. Data were corrected for the diamagnetism contributions of the samples using Pascal constants. The sample holder diamagnetism was measured and subtracted from the raw data.

\section{Synthesis.}

Synthesis of $\mathrm{H}_{4}$ mpba. $3 \mathrm{H}_{2} \mathrm{O}$. Hydrate $\mathrm{N}, \mathrm{N}^{\prime}-1,3$-benzenedioxamic acid was prepared as follows: aqueous $\mathrm{NaOH}(6.22 \mathrm{~g}, 1.55 \mathrm{~mol}, 100 \mathrm{~mL})$ was added dropwise to a suspension of $\mathrm{H}_{2} \mathrm{Et}_{2} \mathrm{mpba}$ $(12 \mathrm{~g}, 38.9 \mathrm{mmol})$ in water $(800 \mathrm{~mL})$. The solution was stirred for $30 \mathrm{~min}$ and filtered. Addition of $4 \mathrm{M}$ $\mathrm{HCl}(38.9 \mathrm{~mL}, 1.55 \mathrm{~mol})$ to the resulting solution leads to the formation of a white precipitate. After 
15 min the precipitate is collected on a sintered glass filter, washed with water and then with $50 \%$ v. EtOH, dried for several hours in air and overnight at $45^{\circ} \mathrm{C}$ in an oven. Yield: $10.9 \mathrm{~g}(91.5 \%) .{ }^{1} \mathrm{H}$ NMR (Bruker Avance 300 MHz, DMSO-d6, 298K) $\delta 10.74(s, 2 H, N H), 8.27(s, 1 H), 7.50$ (d, 2H, $J=7.95 \mathrm{~Hz}), 7.34(\mathrm{t}, 1 \mathrm{H}, \mathrm{J}=8.1 \mathrm{~Hz}) .{ }^{13} \mathrm{C}$ NMR (Bruker Avance $\left.400 \mathrm{MHz}, \mathrm{DMSO}-\mathrm{d} 6,298 \mathrm{~K}\right) \delta$ 112.68, 116.83, 128.86, 137.83, 157.02, 162.11. IR (ATR, cm-1): 3427 s; 3311 m; 3092 s; 2523 s; 1998 s; 1675 s; 1612 m; 1550 m; 1479 s; 1457 s; 1286 m; 1258 m; 1225 s; 1209 m; 1179 s; 1147 s; 1097 s; 993 s; 926 s; 875 s; 822 s; 787 m; 729 s; 678 s; 534 m; 500 m; 408 s; 262 S. Elemental analysis (\%) calculated for $\mathrm{C}_{10} \mathrm{H}_{14} \mathrm{~N}_{2} \mathrm{O}_{9}\left(\mathrm{M}_{\mathrm{r}}=306.22 \mathrm{~g} \mathrm{~mol}^{-1}\right)$ : C 39.22, H 4.60, N 9.14. Found: C 39.21, H 4.44, N 9.07.

Synthesis of $\mathrm{TBA}_{2}\left[\mathrm{Co}_{2}\left(\mathrm{H}_{2} \mathrm{mpba}\right)_{3}\right] .2 \mathrm{DMF} .5 \mathrm{H}_{2} \mathrm{O}, 1 \mathrm{a}: \mathrm{CoCl}_{2} .6 \mathrm{H}_{2} \mathrm{O}(0.119 \mathrm{~g}, 0.5 \mathrm{mmol}), \mathrm{H}_{2} \mathrm{Et}_{2} \mathrm{mpba}$ $(0.153 \mathrm{~g}, 0.5 \mathrm{mmol})$ and TBAOH $(1 \mathrm{M}$ in $\mathrm{MeOH}, 1 \mathrm{~mL}, 1 \mathrm{mmol})$ were placed in a $23 \mathrm{~mL}$ Teflon-lined autoclave filled with DMF $(8 \mathrm{~mL})$ and heated at $100^{\circ} \mathrm{C}$ for 12 hours. After slow cooling to room temperature, pink crystals of $\mathbf{1 a}$ were collected, washed by sonication in DMF and dried in air. Yield: $0.152 \mathrm{~g}\left(39 \%\right.$, based on Co). IR (ATR, cm $\left.{ }^{-1}\right): 3470 \mathrm{~s} ; 3197 \mathrm{~s} ; 3083$ s; 2963 s; $2875 \mathrm{~s}, 1661 \mathrm{~s}$; 1624 S; 1595 S; 1543 S; 1474 S; 1456 m; 1409 s; 1364 S; 1294 m; 1255 s; 1228 s; 1171 s; 1093 s; 1062 s; 1031 s; 988 s; 934 s; 893 s; 837 s; 798 s; 760 s; 739 s; 690 s; 660 s; 598 s; 539 s; 515 s; 473 s; 445 m; 404 s; 357 s; 305 m; 254 S. Elemental analysis (\%) calculated for $\mathrm{C}_{68} \mathrm{H}_{114} \mathrm{Co}_{2} \mathrm{~N}_{10} \mathrm{O}_{25}$ $\left(M_{r}=1589.55 \mathrm{~g} \mathrm{~mol}^{-1}\right)$ : Co 7.41, C 51.38, H 7.22, N 8.81. Found: Co 7.65, C 51.10, H 6.70, N 9.10.

Synthesis of $\left(\mathrm{HNEt}_{3}\right)_{2}\left[\mathrm{Co}_{2}\left(\mathrm{H}_{2} \mathrm{mpba}\right)_{3}\right] .6 \mathrm{DMF} .5 \mathrm{H}_{2} \mathrm{O}, \mathbf{1 b}: \mathrm{CoCl}_{2} .6 \mathrm{H}_{2} \mathrm{O}(0.119 \mathrm{~g}, 0.5 \mathrm{mmol}), \mathrm{H}_{4} \mathrm{mpba}$ $(0.154 \mathrm{~g}, 0.5 \mathrm{mmol})$ and $\mathrm{NEt}_{3}(99 \%, 0.28 \mathrm{~mL}, 2 \mathrm{mmol})$ were placed in a $23 \mathrm{~mL}$ Teflon-lined autoclave filled with DMF $(9 \mathrm{~mL})$ and heated at $100^{\circ} \mathrm{C}$ for 12 hours. After slow cooling to room temperature, red-brown crystals of $\mathbf{1} \mathbf{b}$ were collected, washed by sonication in DMF and dried in air. Yield: $0.043 \mathrm{~g}\left(11 \%\right.$, based on Co). IR $\left(A T R, \mathrm{~cm}^{-1}\right): 3435$ s; 3197 s; 3084 s; 1621 s; 1595 S; 1545 S; 1475 s; 1456 m; 1364 s; 1295 m; 1255 s; 1229 s; 1174 s; 1094 s; 1062 s; 1034 s; 988 s; 934 s; 892 s; 837 s; 799 s; 760 s; 689 s; 660 s; 598 s; 538 m; 517 s; 444 m; 405 s; 357 m; 307 s; 251 s; $214 \mathrm{~m}$. Elemental analysis (\%) calculated for $\mathrm{C}_{60} \mathrm{H}_{102} \mathrm{Co}_{2} \mathrm{~N}_{14} \mathrm{O}_{29}\left(\mathrm{M}_{\mathrm{r}}=1601.39 \mathrm{~g} \mathrm{~mol}^{-1}\right): \mathrm{C} 45.0, \mathrm{H} 6.42$, N 12.24. Found: C 44.65, H 6.06, N 12.46.

Synthesis of $\operatorname{TBA}_{2}\left[\mathrm{Ni}_{2}\left(\mathrm{H}_{2} \mathrm{mpba}\right)_{3}\right] .2 \mathrm{DMF} .2 .5 \mathrm{H}_{2} \mathrm{O}, 2: \mathrm{NiCl}_{2} .6 \mathrm{H}_{2} \mathrm{O}(0.119 \mathrm{~g}, 0.5 \mathrm{mmol}), \mathrm{H}_{2} \mathrm{Et}_{2} \mathrm{mpba}$ $(0.154 \mathrm{~g}, 0.5 \mathrm{mmol})$ and TBAOH $(1 \mathrm{M}$ in $\mathrm{MeOH}, 1 \mathrm{~mL}, 1 \mathrm{mmol})$ were placed in a $23 \mathrm{~mL}$ Teflon-lined autoclave filled with DMF $(8 \mathrm{~mL})$ and heated at $100^{\circ} \mathrm{C}$ for 12 hours. After slow cooling to room temperature, green crystals of $\mathbf{2}$ were collected, washed by sonication in DMF and dried in air. Yield: 0,111 g (29\%, based on Ni). IR (ATR, cm"): 3463 s; 3229 s; 3084 s; 2963 s; 2875 s; 1662 m; 1625 S; 1595 S; 1545 S; 1474 s; 1457 s; 1409 s; 1366 S; 1295 s; 1255 s; 1229 s; 1171 s; 1094 s; 
1062 s; 1031 s; 988 s; 935 s; 894 s; 837 s; 802 m; 762 s; 739 s; 690 s; 660 s; 599 s; 540 s; 517 s; 499 s; 483 s; 462 s, 446 s; 406 s; 360 s, 318 m; 274 m. Elemental analysis (\%) calculated for $\mathrm{C}_{68} \mathrm{H}_{109} \mathrm{~N}_{10} \mathrm{Ni}_{2} \mathrm{O}_{22.5}\left(\mathrm{Mr}_{\mathrm{r}}=1544 \mathrm{~g} \mathrm{~mol}^{-1}\right): \mathrm{Ni} 7.60, \mathrm{C} 52.89, \mathrm{H}$ 7.11, N 9.07. Found: $\mathrm{Ni}$ 8,10, C 50.74, H $6.75, \mathrm{~N} 9.6$.

Synthesis of $\left(\mathrm{HNEt}_{3}\right)_{2}\left[\mathrm{Co}_{2}\left(\mathrm{H}_{2} \mathrm{mpba}\right)_{3}\right], 3: \mathrm{CoCl}_{2} .6 \mathrm{H}_{2} \mathrm{O}(0.119 \mathrm{~g}, 0.5 \mathrm{mmol}), \mathrm{H}_{4} \mathrm{mpba} .3 \mathrm{H}_{2} \mathrm{O}(0.153 \mathrm{~g}$, $0.5 \mathrm{mmol})$ and $\mathrm{NEt}_{3}(99 \%, 0.280 \mathrm{~mL}, 2 \mathrm{mmol})$ were placed in a $23 \mathrm{~mL}$ Teflon-lined autoclave filled with DMF $(9 \mathrm{~mL})$ and heated at $150^{\circ} \mathrm{C}$ for 12 hours. After slow cooling to room temperature, purple crystals of $\mathbf{3}$ were collected, washed by sonication in DMF and dried in air. Yield: $0.135 \mathrm{~g}$ (50.3\%, based on Co). IR (ATR, cm $): 3228$ s; 1631 S; 1598 S; 1540 m; 1475 m; 1456 m; 1361 S; 1290 m; 1233 s; 1161 s; 1017 s; 979 s; 934 s; 885 s; 800 s; 707 s; 684 m; 630 s; 604 s; 545 m; 509 m; 439 m; 407 s; 358 s; 296 m; 273 s; 243 S. Elemental analysis (\%) calculated for $\mathrm{C}_{42} \mathrm{H}_{50} \mathrm{Co}_{2} \mathrm{~N}_{8} \mathrm{O}_{18}$ $\left(M_{r}=1072.75 \mathrm{~g} \mathrm{~mol}^{-1}\right):$ Co 10.98, C 47.02, H 4.69, N 10.44. Found: Co 10.66, C 47.56, H 4.64, N 10.66 .

\section{Crystallographic studies.}

Data were collected on a Bruker Kappa-APEX II CCD diffractometer for $\mathbf{1 b}$ and $\mathbf{3}$ (MoK, = $0.71069 \AA$ A). Crystals were mounted on a Hamilton cryoloop using Paratone-N oil and placed in the cold flow produced with an Oxford Cryocooling device. Partial hemispheres of data -predefined with the APEX II software ${ }^{28 a}$ - were collected using $\phi$ and scans $(110 \mathrm{~s} /$ frame for $\mathbf{1 b}, 100 \mathrm{~s} /$ frame for 3). Integrated intensities were obtained with SAINT+ ${ }^{28 a}$ and were corrected for absorption with SADABS ${ }^{28 b, c}$; structure solution and refinement was performed with the SHELXTL-package.28a The structures were solved by direct methods and completed by iterative cycles of $\Delta F$ syntheses and full-matrix least-squares refinement against $F^{2}$. 1a, $\mathbf{1 b}$ and $\mathbf{2}$ are poorly diffracting and despite numerous efforts the best data set obtained, for $\mathbf{1} \mathbf{b}$, still gives some large reliability factors and restraints have been used to model counter-ions and solvent molecules. Crystallographic data and refinements parameters for $\mathbf{1} \mathbf{b}$ and $\mathbf{3}$ are given in Table 1.

X-ray powder diffraction patterns for $\mathbf{1 a}, \mathbf{1} \mathbf{b}$ and $\mathbf{2}$ are presented in the Figure S1 of the supplementary information. Diagrams were collected on a Philips X'pert Pro diffractometer using CuK 1 monochromatised radiation $(=1.54060 \AA$ ) and equipped with a X'celerator linear detector. 
Table 1 Crystallographic data for compounds $1 \mathrm{~b}$ and 3

\begin{tabular}{|c|c|c|}
\hline & $1 b$ & 3 \\
\hline Formula $^{a}$ & $\mathrm{C}_{51} \mathrm{H}_{91} \mathrm{CO}_{2} \mathrm{~N}_{11} \mathrm{O}_{31}$ & $\mathrm{C}_{42} \mathrm{H}_{50} \mathrm{Co}_{2} \mathrm{~N}_{8} \mathrm{O}_{18}$ \\
\hline $\mathrm{FW}\left[\mathrm{g} \mathrm{mol}^{-1}\right]$ & 1472.21 & 1072.75 \\
\hline Crystal system & Trigonal & Monoclinic \\
\hline Space group & $R-3 c$ & $P 2_{1}$ \\
\hline$a[\AA]$ & $17.527(7)$ & $10.3375(6)$ \\
\hline$b[\AA]$ & $17.527(7)$ & $15.2574(15)$ \\
\hline$c[\AA]$ & $46.452(7)$ & $15.0870(15)$ \\
\hline$\alpha\left[^{\circ}\right]$ & 90 & 90 \\
\hline$\beta\left[^{\circ}\right]$ & 90 & $91.745(7)$ \\
\hline$\gamma\left[{ }^{\circ}\right]$ & 120 & 90 \\
\hline$V\left[\AA^{3}\right]$ & 12359(3) & $2378,5(4)$ \\
\hline Z & 6 & 2 \\
\hline$T[\mathrm{~K}]$ & $200(2)$ & $200(2)$ \\
\hline$\lambda[\AA ̊]$ & 0.71073 & 0.71073 \\
\hline$\rho_{\text {calc }}\left[\mathrm{g} \mathrm{cm}^{-3}\right]$ & 1.187 & 1.498 \\
\hline$\mu$ (Мока) $\left[\mathrm{mm}^{-1}\right]$ & 0.480 & 0.780 \\
\hline$F(000)$ & 4656 & 1112 \\
\hline Crystal size $[\mathrm{mm}]$ & $0.32 \times 0.19 \times 0.17$ & $0.31 \times 0.15 \times 0.15$ \\
\hline$\theta$ limits $\left[{ }^{\circ}\right]$ & $2.21-24.99$ & $3.01-30.01$ \\
\hline Measured reflections & 19834 & 28005 \\
\hline Unique reflections & 2416 & 12852 \\
\hline$R_{\text {int }}$ & 0.0960 & 0.0345 \\
\hline Reflections $\mid>2 \sigma(I)$ & 1595 & 9744 \\
\hline Parameters & 124 & 633 \\
\hline Restraints & 9 & 1 \\
\hline$R_{1}^{b}[1>2 \sigma(I)]$ & 0.0849 & 0.0422 \\
\hline$w R_{2}^{c}$ & 0.2981 & 0.0955 \\
\hline GOF & 1.135 & 1.000 \\
\hline Largest residuals $\left[\mathrm{e} \AA^{3}\right]$ & $-0.543 ; 1.823$ & $-0.319 ; 0.429$ \\
\hline \multicolumn{3}{|c|}{${ }^{a}$ Including solvate molecules. ${ }^{\mathrm{b}} \quad \boldsymbol{R}_{1}=\Sigma|| \boldsymbol{F}_{o}|-| \boldsymbol{F}_{c}|/ \Sigma| \boldsymbol{F}_{o} \mid$} \\
\hline${ }^{c} \omega \boldsymbol{R}_{2}=\left[\Sigma\left(\omega\left(F_{o}^{2}-F_{c}^{2}\right)^{2}\right) / \Sigma(\right.$ & )$\left.\left.^{2}\right)\right]^{1 / 2}$ & \\
\hline
\end{tabular}




\section{RESULTS AND DISCUSSION}

Compounds $\mathbf{1 a}, \mathbf{1} \mathbf{b}$ and $\mathbf{2}$ are isostructural and crystallise in the $R-3 c$ centrosymetric space group with an asymmetric unit that consists of one sixth of the bimetallic complex. Each complex is made of two divalent ions in octahedral geometry bridged by three partially deprotonated $\left(\mathrm{H}_{2} \mathrm{mpba}\right)^{2-}$ ligands. The metal ions bind two oxygen atoms from the oxamate groups leaving one carbonyl and one amido function uncoordinated. Such a binding mode arises from the non-deprotonation of the amido groups -independently of the strength of the base used in the reaction - and results in the formation of a triple-stranded chiral helicate complex where the oxamate groups lie in the plane of the benzyl rings (Figure 1b).

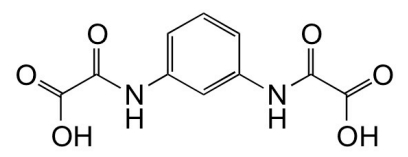

a)

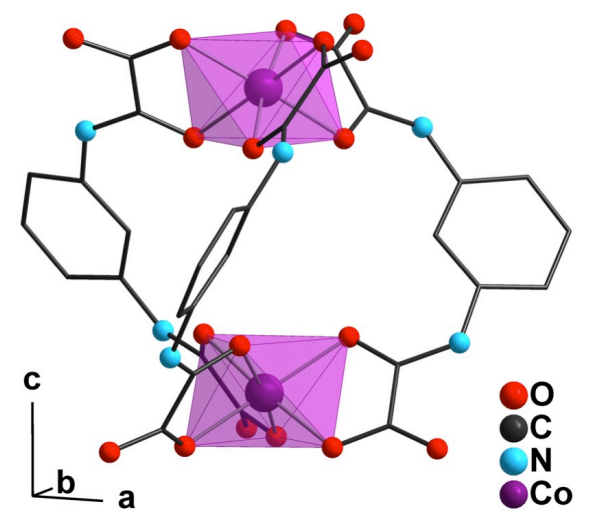

b)

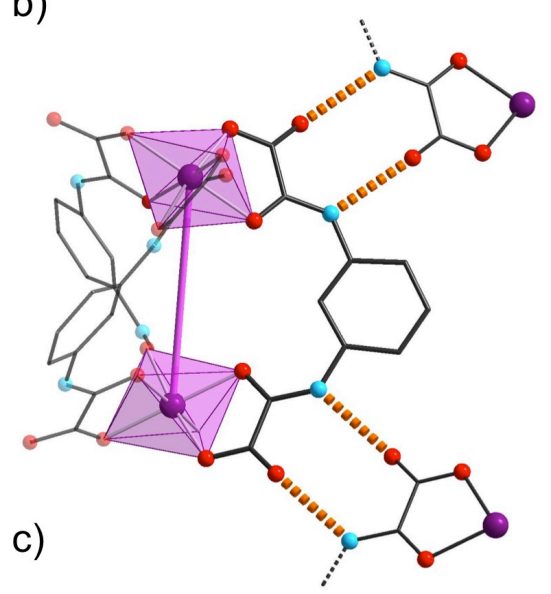

Figure 1. a) representation of the 1,3-benzenedioxamic acid; b) structure of the anionic complex in $\mathbf{1 b} \mathbf{1} \mathbf{a}$, with legend as an inset, $\mathrm{H}$ atoms are omitted for clarity; c) Representation of the $\mathrm{N}(-\mathrm{H}) \cdots \mathrm{O}$ bond (orange dotted lines) between adjacent molecules in $\mathbf{1} \mathbf{b} ; \mathbf{H}$ atoms are omitted for clarity; the dinuclear complex is schemed with an intramolecular Co-Co bound pictured in purple.

The formation of multiple hydrogen bonds between the amide (proton donor) and carbonyl (proton acceptor) functions of oxamic acids from adjacent complexes leads to a 3D framework composed of 2D hexagonal layers and pillared by the helicoidal complexes (Fgure 1c and 2). The 
found $\mathrm{N}(-\mathrm{H}) \cdots \mathrm{O}$ distance of $2.81(1) \AA$ is relatively short in comparison to the intermolecular $\mathrm{H}$ bond distances reported for the $\mathrm{H}_{2} \mathrm{Et}_{2} \mathrm{mpba}$ ligand. ${ }^{29-30}$ The $2 \mathrm{D}(6,3)$ hexagonal networks are composed of cobalt octahedra linked via their edges by double $\mathrm{H}$-bonds through the oxamate groups and it is now well established that a 2D net made of octahedra sharing edges is only obtained for a perfect alternation of and $\Delta$ isomers. ${ }^{31-33-\ddagger}$ Therefore both enantiomers of the helicate are found in the structure and are alternatively linked to one another through the double $H$-bonds to yield the heterochiral honeycomb-like framework $A_{4}\left[\Delta-M \Delta-M(H m p b a)_{3}\right][-M-$ $\left.\mathrm{M}(\mathrm{Hmpba})_{3}\right]\left(\mathrm{A}=\mathrm{TBA}^{+}, \mathrm{HNEt}_{3}{ }^{+}, \mathrm{M}=\mathrm{Ni}, \mathrm{Co}\right)$ (Figure 2). It is worth noticing that the $\mathrm{H}$-bonds seem to solely drive the three-dimensional arrangement of the complexes since no obvious structural differences could be observed between the $\mathrm{TBA}^{+}$and the $\mathrm{HNEt}_{3}{ }^{+}$salts. The formation of this relatively strong supramolecular network could potentially tend to stabilize the helicate complex and limit the deprotonation of the ligands.

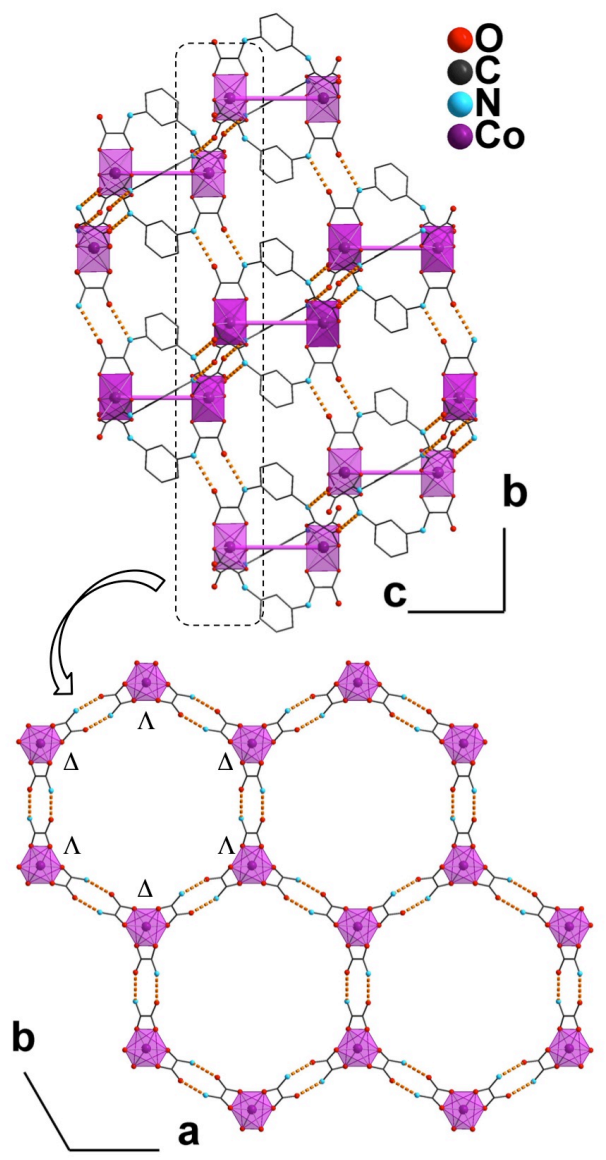

Figure 2. Crystal packing of $\mathbf{1 b}$ showing the $\mathrm{H}$-bond structuring (orange dotted lines) into a heterochiral hexagonal 3D network; $\mathrm{H}$ atoms are omitted for clarity; dinuclear complexes are schemed with an intramolecular Co-Co bound pictured in purple in the $(\mathrm{bc})$ plane; benzyl rings are omitted for clarity in the representation of the (ab) plane.

‡ On the other hand, a 3D $(10,3)$ chiral framemork is obtained for enanantiopure octahedra sharing edges see for instance M. Gruselle et al., Coord. Chem. Rev., 2006, 250, 2491. 
This binding mode of the $\left(\mathrm{H}_{\mathrm{x}} \mathrm{mbpa}\right)^{(4-x)}$ - ligand is encountered for the first time. Indeed, under bench conditions and in aqueous media, the fully deprotonated form of the ligand (mbpa) ${ }^{4-}$ also binds octahedral ions in a 3:2 fashion but affords a heterochiral triple-stranded mesocate bimetallic complex $\left[\mathrm{Co}_{2}(\mathrm{mpba})_{3}\right]^{8-}$ where the oxamate groups are perpendicular to the benzyl rings (Figure 3a). ${ }^{20}$ This difference in the geometrical arrangement in $\mathbf{1} \mathbf{b}$ and in $\left[\mathrm{Co}_{2}(\mathrm{mpba})_{3}\right]^{8-}$ changes the relative orientation of the coordination polyhedra between the two halves of the dinuclear complexes. In $\mathbf{1} \mathbf{b}$ the two polyhedra have a staggered conformation when viewing along the CoCo axis whereas in $\left[\mathrm{CO}_{2}(\mathrm{mpba})_{3}\right]^{8-}$ the two polyhedra have an eclipsed conformation (Figure $3 \mathrm{~b}$ and 3c). Consequently these conformations lead to different networks. In $\mathbf{1} \mathbf{b}$, the double $\mathrm{H}$-bonds between adjacent complexes lead to a stacking of staggered hexagonal networks (Figure 4a) with the same topology than diamond or sphalerite structures i.e. "dia" net in RCSR database ${ }^{34}$ whereas in $\mathrm{Li}_{5}\left[\mathrm{Li}_{3} \mathrm{Co}_{2}(\mathrm{mpba})_{3}\left(\mathrm{H}_{2} \mathrm{O}\right)_{6}\right] \cdot 31 \mathrm{H}_{2} \mathrm{O}$, the coordination of the two cis carbonyl-oxygen atoms of the oxamato groups to $\mathrm{Li}^{+}$ions leads to 3D honeycomb framework with hexagonal channels and is topologically like the lonsdaleite or wurtzite structures i.e. "Ion" in RCSR database. By contrast, the staggered conformation of the helicate does not lead to large pore in $\mathbf{1} \mathbf{b}$.

a)

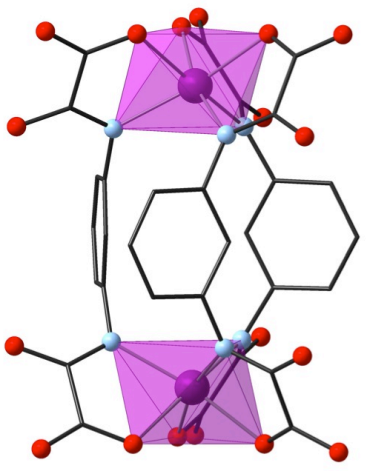

b)

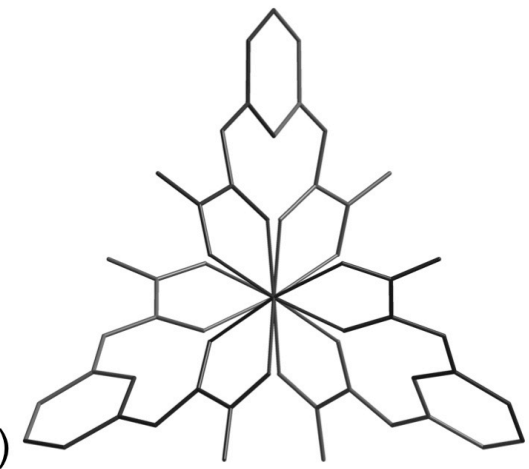

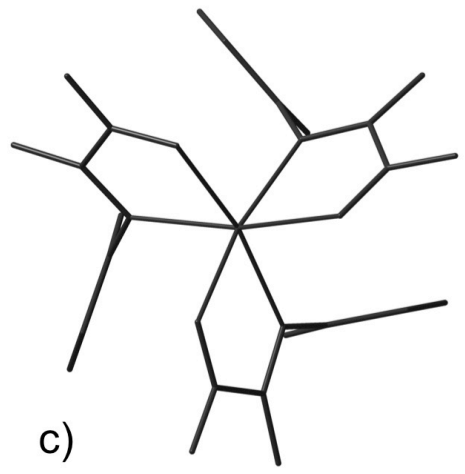

Figure 3. a) structure of the anionic complex $\left[\mathrm{Co}_{2}(\mathrm{mpba})_{3}\right]^{8-20}$ b) Stick model of $\mathbf{1} \mathbf{b}$ along the Co-Co axis, c) Stick model of $\left[\mathrm{Co}_{2}(\mathrm{mpba})_{3}\right]^{8-}$ along the $\mathrm{Co}-\mathrm{Co}$ axis. 

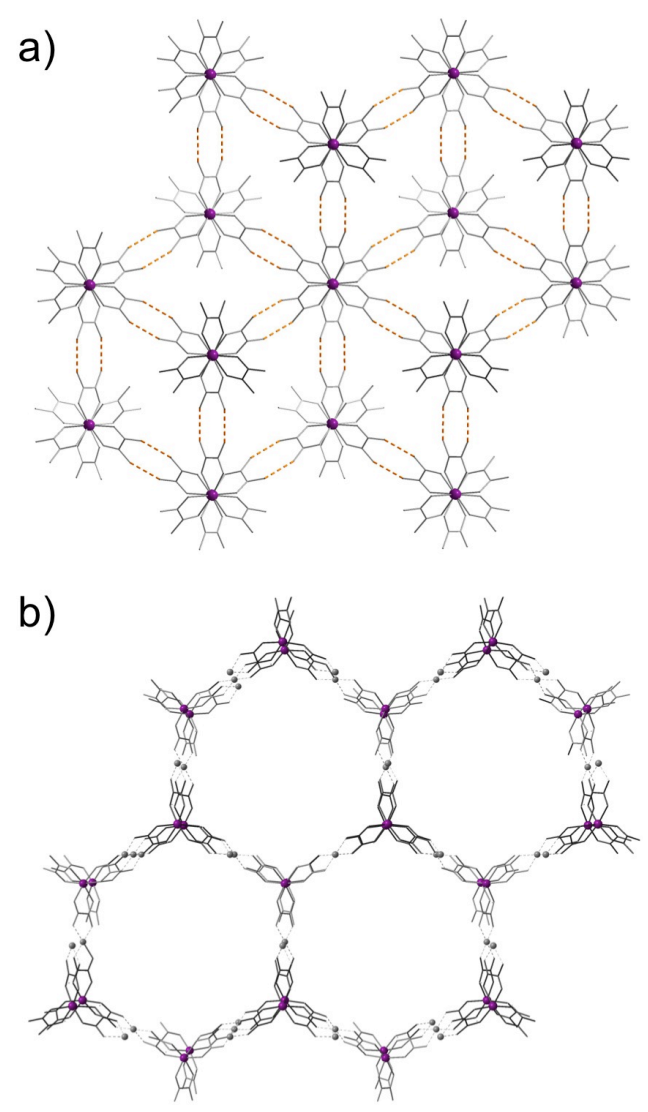

Figure 4. Staking of hexagonal networks in a) $\mathbf{1} \mathbf{b}$ and b) in $\left[\mathrm{Li}_{3} \mathrm{Co}_{2}(\mathrm{mpba})_{3}\left(\mathrm{H}_{2} \mathrm{O}\right)_{6}\right]^{5-}$; benzyl rings are omitted for clarity.

Compound 3 crystallises in the $P 2{ }_{1}$ chiral space group and a whole complex is found in the asymmetric unit. The bimetallic complex is identical to the previously described compounds however there are drastic differences in the 3D layout since the $\mathrm{H}$-bond-driven arrangement of the bimetallic species leads to a homochiral framework (Figure 5). The $\mathrm{H}$-bond network is far more complex than in the previous cases with each ligand of the same molecular unit displaying a different $\mathrm{H}$-bonding mode to two or three adjacent molecules (Figure 6). Triethylammonium cations also form hydrogen bonds with the carbonyl groups of the ligand and are located in the cavities of the distorted hexagonal architecture defined by the metallic complexes (Figure S1 in the Supporting Information). The intermolecular $\mathrm{N}(-\mathrm{H}) \cdots \mathrm{O}$ distances found in the structure range from $2.8708(2)$ to $3.0886(3) \AA$ with a mean value of $2.97 \AA$. One can suppose that performing the reaction at 150 instead of $100^{\circ} \mathrm{C}$ leads to a higher autogenous pressure during the solvothermal treatment which in turn constrains the system to stabilise into a denser phase and hence this more complex $\mathrm{H}$-bond networking. The consequence of this densification is the lack of one of the two enantiomers of the bis-cobalt(II) helicate in the hexagonal lattice. Although distorted, the hexagonal lattice is still visible in Figure 5 with vertices alternatively defined by cobalt ocathedra and the entanglement of hydrogen bonds leading then to an enantiopure network. 
No signals were found in circular dichroism measurements performed on the bulk material indicating that both enantiomers $\left(\mathrm{HNEt}_{3}\right)_{2}\left[\Delta-\mathrm{Co} \Delta-\mathrm{Co}(\mathrm{Hmpba})_{3}\right]$ and $\left(\mathrm{HNEt}_{3}\right)_{2}\left[-\mathrm{Co}-\mathrm{Co}(\mathrm{Hmpba})_{3}\right]$ crystallise out from the solvothermal reaction. Attempts to measure circular dichroism data on a single crystal diluted in $\mathrm{KBr}$ proved unsuccessful whereas measurement in solution were made impossible since compound $\mathbf{3}$ is insoluble in most common solvents, including DMSO or DMF.

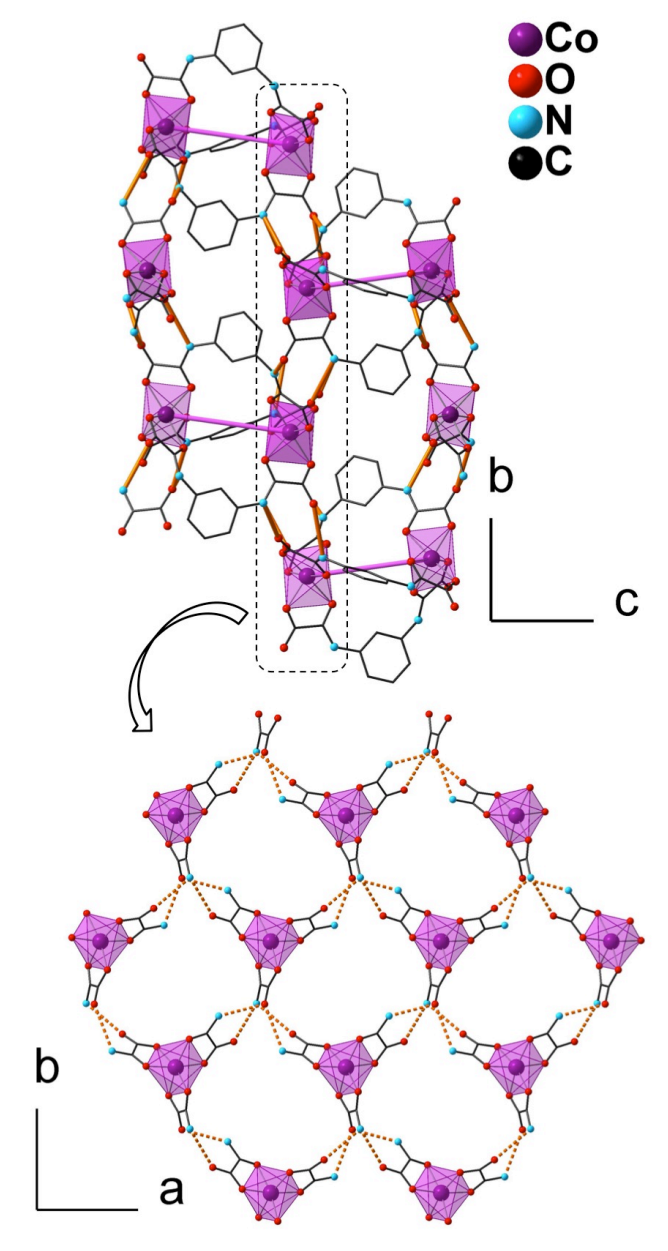

Figure 5. Crystal packing of 3 showing the $\mathrm{H}$-bond structuring (orange dotted lines) into a homochiral 3D network; $\mathrm{H}$ atoms are omitted for clarity; dinuclear complexes are schemed with an intramolecular Co-Co bound pictured in purple in the (bc) plane; benzyl rings are omitted for clarity in the representation of the (ab) plane. 

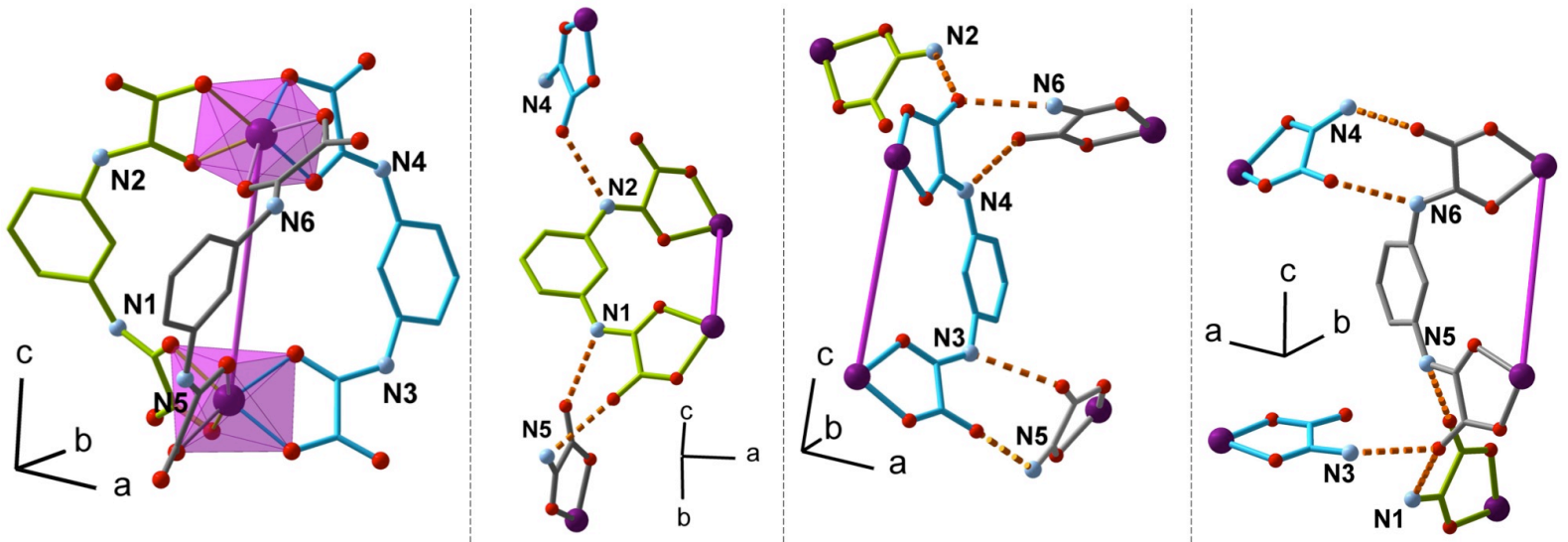

Figure 6. Schematic view of the $\mathrm{N}(-\mathrm{H}) \cdots \mathrm{O}$ bonds (orange dotted lines) between adjacent molecules in $\mathbf{3} ; \mathrm{H}$ atoms are omitted for clarity; the dinuclear complex is schemed with an intramolecular Co-Co bound pictured in purple.

Magnetic properties. Magnetic measurements in DC mode were performed on all compounds (Figure 7). At room temperature, the $\chi_{M} . T$ values, approx. $6.5 \mathrm{~cm}^{3} . \mathrm{K}_{\mathrm{mol}}{ }^{1}$ for $\mathbf{1 a}, \mathbf{1} \mathbf{b}$ and $\mathbf{3}$, are close to the expected one for two isolated $\mathrm{Co}(\mathrm{II})$ ions. Upon cooling, the $\chi_{\mathrm{M}} . T$ products steadily decrease and reach $3.7 \mathrm{~cm}^{3} . \mathrm{K} \mathrm{mol}{ }^{1}$ at $2 \mathrm{~K}$. In the $300-2 \mathrm{~K}$ temperature range, the experimental curves can be modelled using the theoretical behaviour of two isolated distorted octahedral cobalt(II) ions. ${ }^{35}$ The best fit of the data obtained by full-matrix diagonalisation of the appropriate spin Hamiltonian gave $\lambda=-128 \mathrm{~cm}^{-1}, \mathrm{D}=-391 \mathrm{~cm}^{-1}$ and $\alpha=0.99$ for $1 \mathrm{a} ; \lambda=-179 \mathrm{~cm}^{-1}, \mathrm{D}=-565 \mathrm{~cm}^{-}$ ${ }^{1}$ and $\alpha=0.76$ for $\mathbf{1 b}$ and $\lambda=-168 \mathrm{~cm}^{-1}, \mathrm{D}=-494 \mathrm{~cm}^{-1}$ and $\alpha=0.79$ for $\mathbf{3}$ where $\lambda, D$ and $\alpha$ are the spin orbit coupling constant, the distortion parameter and reduction parameter of spin orbit coupling respectively. The theoretical curves reproduce quite well the experimental data over the whole range of temperature showing that there is no interaction between the cobalt ions within the helicates. For the bis-nickel helicate 2, the $\chi_{\mathrm{M}} . T$ value remains constant in the 300-100 K temperature range and is equal to $2.2 \mathrm{~cm}^{3} \cdot \mathrm{K} \cdot \mathrm{mol}^{-1}$ which is close to the expected one for two magnetically isolated $\mathrm{Ni}(\mathrm{II})$ ions. Below $100 \mathrm{~K}$, the value of $\chi_{\mathrm{M}} . T$ slowly decreases to reach a value of $1.9 \mathrm{~cm}^{3} . \mathrm{K} \mathrm{mol}^{-1}$ at $2 \mathrm{~K}$. This behaviour could be interpreted either by a very weak interaction between the two $\mathrm{Ni}(\mathrm{II})$ ions within the helicate or by the effect of the zero field splitting of the individual $\mathrm{Ni}(\mathrm{II})$ ions. The best data fits gave $\mathrm{g}=2.1, \mathrm{~J}=-0.6 \mathrm{~cm}^{-1}$ for the first model and $\mathrm{g}_{\mathrm{Ni}}=2.1$ and $D_{N i}=-6.5 \mathrm{~cm}^{-1}$ for the second one. The agreement factor $R=\left[\left(\chi_{M} T\right)_{\exp }-\left(\chi_{M} T\right)_{\text {calcd }}\right] 2 /\left[\left(\chi_{M} T\right)_{\exp }\right]^{2}$ is slightly better for the first model with values equal to $R=10^{-4}$ and $2.10^{-4}$ respectively. However, the lack of interaction in the cobalt-based helicates leads us to favour the second model.

The lack of interaction in these helicates contrasts with the results obtained for the cobalt and nickel mesocates - in which the $(\mathrm{mpba})^{4-}$ ligand is deprotonated - where a weak but noticeable ferromagnetic interaction is observed with $\mathrm{J}=1 \mathrm{~cm}^{-1}$ and $\mathrm{J}=3.6 \mathrm{~cm}^{-1}$ respectively. ${ }^{20,36}$ This 
difference in the magnetic behaviour is explained by the relative orientation of oxamate groups with the benzene rings. In the helicate family the oxamate groups are almost in the same plane as the benzene cycles. As a consequence the interaction between the magnetic orbitals of the cobalt or nickel ions and the $\pi$ orbitals of the benzene rings is very weak and there is no efficient pathway with the bonds of the benzene rings. On the contrary, in the mesocates the oxamate groups are perpendicular to the benzene ring, this conformation allows a $\sigma$ overlap between the $e_{g}$ magnetic orbitals and the lone pair of the deprotonated amide nitrogen atom which are in strong interaction with the extended $\pi$ conjugated bond system of the phenylene spacers. ${ }^{37}$ This situation leads to a quite large spin polarization effect through the $\pi$ orbitals of the benzene rings and despite a metalmetal distance that goes up $6.85 \AA$ - which is actually longer than in the case of the helicates there is a magnetic interaction in the mesocate family. The simple protonation or deprotonation of the mpba ligands completely change the magnetic properties of the dinuclear compounds from ferromagnetic coupling to an uncoupled system and this is a perfect illustration that the important parameter in the exchange interaction is not primarily the metal-metal distance but the existence of molecular orbitals able to transmit the interaction.
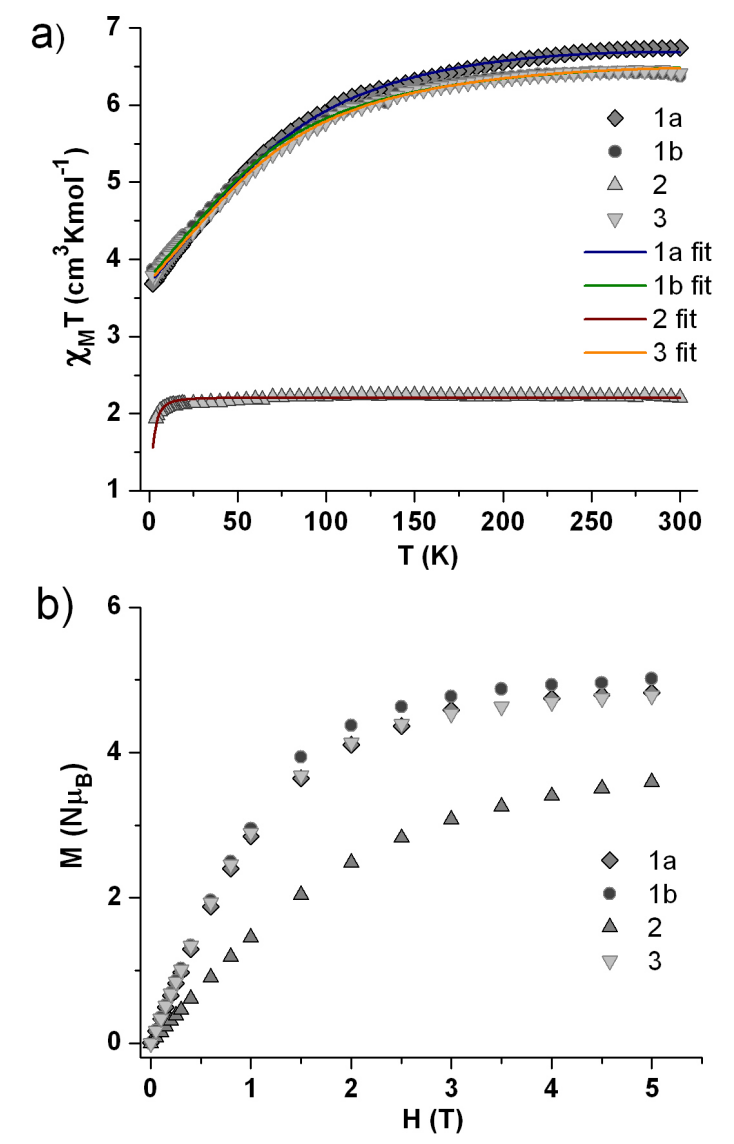

Figure 7. a) Plots of $\chi_{M} T$ vs. $T$ measured from 300 to $2 \mathrm{~K}$ at $1 \mathrm{kOe}$ for $\mathbf{1 a}(\diamond), \mathbf{1 b}(\mathbf{0}), \mathbf{2}(\mathbf{\Delta})$ and $\mathbf{3}(\nabla)$ and respective fits in solid line: $\mathbf{1 a}$-blue, $\mathbf{1} \mathbf{b}$-green, $\mathbf{2}$-red, $\mathbf{3}$-orange; b) plots of $M \mathrm{vs}$. $\mathrm{H}$ measured from 0 to $7 \mathrm{~T}$ at $2 \mathrm{~K}$ for $\mathbf{1 a}(\diamond), \mathbf{1 b}(\mathbf{\bullet}), \mathbf{2}(\Delta)$ and $\mathbf{3}(\nabla)$. 
Discussion. Unexpectedly, solvothermal synthesis using polyoxalamide ligands has led to new coordination compounds with ligands bearing double $\mathrm{H}$-bonds sites. These complexes are built from metal ions and partially protonated ligands comprising oxamide anions. Oxamide anions are known to be flexible building blocks for hydrogen-bonded architectures. ${ }^{38}$ Indeed, the compounds presented in this paper are interesting examples of networks built simultaneously from coordination complexes and complementary hydrogen bonding sites. ${ }^{39-41}$ In inorganic crystal engineering this strategy is, in theory, very effective. The geometrical preferences of the coordination sphere of the metal ions (square planar, octahedral, etc...) induce a precise orientation of hydrogen-bonding groups that can also propagate geometrical information which would lead, in principle, to predictable results. In practice, the situation is less clear. For instance, with 2,2-bisimidazolato tris-chelate complex building blocks the directions of the $\mathrm{H}$-bonds are coplanar and separated by an angle of $120^{\circ}$ so the obvious construction is a honeycomb network and some results confirm this expectation. ${ }^{42}$ However, there are several examples of more complicated structures which includes interpenetrating nets ${ }^{42}$, achiral ${ }^{43}$, racemate $^{44}$ and chiral 3D structures. ${ }^{45}$ Even, OD, 1D zig-zag and 1D helical structures were obtained. ${ }^{43,46}$ Switching from one structure to another depends on other subtle intermolecular interactions, such as the role of the counter ions or the control of the chirality of the metal-ions coordination sphere. Therefore, whatever the type of connection used to form a network either by hydrogen bonds or coordination bonds, if tris-chelate complex building blocks appear as a reliable way to obtain self-organized 2D or $3 D$ nets, the final dimensionality remains difficult to predict. This is especially true for $3 D$ nets as they seem difficult to achieve although it is not completely unexpected since a basic unit bearing six connecting points is necessary to build a $3 \mathrm{D}$ net by translation. ${ }^{47-48}$ Consequently, a tris-chelate building block with only three connecting points does not meet this requirement. Since the basic unit must be connected to six others, it is then compulsory to have at least four tris-chelate in the basic unit in order to build a 3 connected 3D net, i.e. a tetranuclear complex as building block (scheme 1). In the case of monomeric metal complexes, only an octahedral complex with six bismonodentate ligands like hexacyanometallates is able to build a 3D network. ${ }^{49-50}$ For dinuclear building blocks it is necessary to have a connectivity of four at each node to obtain 3D networks and the helicates described in this paper meet this requirement. 


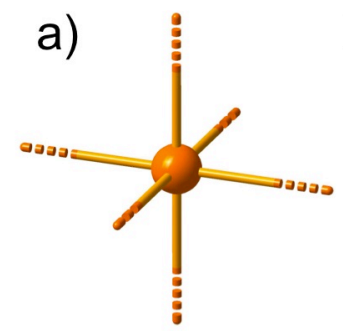

b)

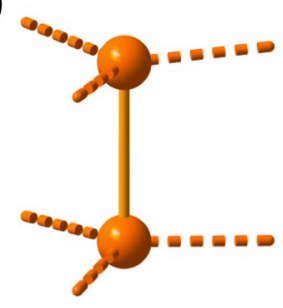

c)
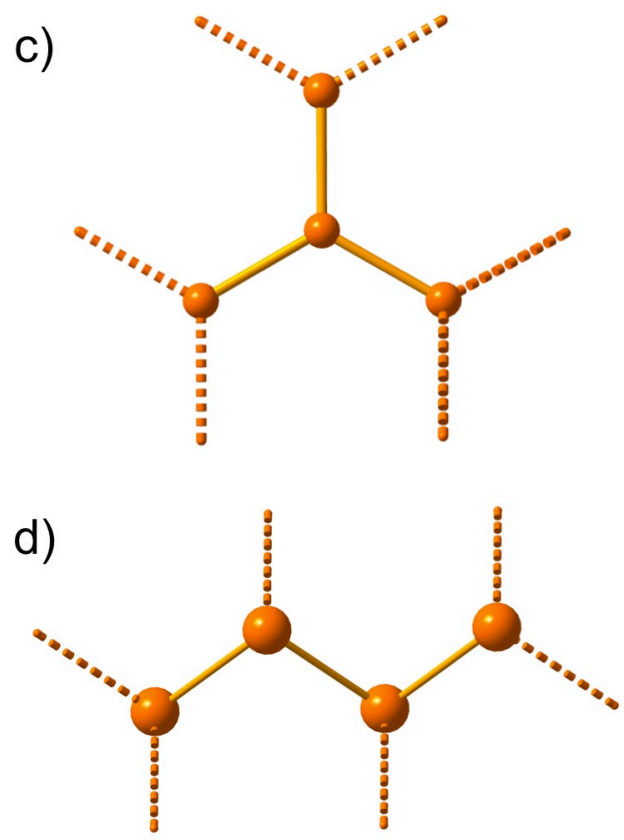

Scheme 1. Simplest building block providing the 6 necessary connecting points to build 3D nets: (a) mononuclear, (b) dinuclear, (c) and (d) tetranuclear.

Actually, these new helicates complexes bearing six double $\mathrm{H}$-bonds sites illustrate nicely the "recipe" A.F. Wells proposed in the fifties to build a 3D 4 connected net, ${ }^{51-52}$ " The simplest planar 3- connected net is the hexagonal net with 2 points in the repeat unit. By connecting alternate points to points in layers above and below there arises the simplest three- dimensional 4connected net». This description corresponds to the exact structure of compound $\mathbf{1 b}$. Furthermore, owing to the structure of the helicate, the resulting net in $\mathbf{1} \mathbf{b}$ was perfectly predictable. However, it should be noted that the structure of $\mathbf{3}$ with the entanglement of hydrogen bonds that results from a temperautue effect was not anticipated even though the same initial synthon is present. To summarize, the dinuclear triple-stranded helicates or mesocates are perfect building blocks to obtain 3D networks because they offer the six required connecting points. It is worth noting that the polynuclear complexes $\left\{\mathrm{Zn}_{4} \mathrm{O}\left(\mathrm{RCO}_{2}\right)_{6}\right\}$ and $\left\{\mathrm{Cr}_{3} \mathrm{O}\left(\mathrm{RCO}_{2}\right)_{6}\right\}$ which are used as SBU (Secondary Building Units) in 3D MOF $5^{53}$ and MIL $101^{54}$ also possess 6 connecting points. 


\section{CONCLUSION}

Solvothermal synthesis has successfully led to novel chiral helicate oxamate-based dinuclear complexes where supramolecular $\mathrm{H}$-bond networking in the solid influenced by the synthesis temperature leads to 3D diamond like or 3D chiral structures. From these results obtained fortuitously, it is possible to conclude that, as in the synthesis of MOF, the use of polynuclear metal complexes as building blocks is a good strategy to build 3D networks in a predictable and controlled way. To the best of our knowledge, the strategic use of dicrete polymeatllic coordination compounds bearing hydrogen bond sites specifically designed to construct networks rationnaly has not been explored so far in crystal engineering and the present results open a synthetic route that is worth following. There had been no example of oxamate-based coordination compounds obtained solvothermally and this preliminary study is thus promising. Indeed the use of solvothermal conditions combined to the rich family of ligands that oxamate derivatives constitute clearly opens a new synthetic route towards multidimensional molecular magnetic materials.

\section{ACKNOWLEDGMENT}

This work was supported by the Ministère de la Recherche et de I'Enseignement Supérieur (MRES) and the Centre National de la Recherche Scientifique (CNRS).

\section{SUPPORTING INFORMATION AVAILABLE}

X-ray crystallographic files for $1 \mathrm{~b}$ and 3 in CIF format; figures showing: (i) Experimental X-ray powder diffraction patterns for $\mathbf{1} \mathbf{a}, \mathbf{1} \mathbf{b}$ and $\mathbf{2}$ and calculated patterns for $\mathbf{1 a}$ and $\mathbf{1} \mathbf{b}$, (ii) intermolecular hydrogen bonds between the bimetallic complex and its $\mathrm{HNEt}_{3}{ }^{+}$counter-ions in 3 . This information is available free of charge via the Internet at http://pubs.acs.org.

\section{REFERENCES}

(1) Aakeroy, C. B.; Champness, N. R.; Janiak, C. CrystEngComm 2010, 12, 22-43.

(2) Robson, R. J. Chem. Soc., Dalton Trans. 2000, 3735-3744.

(3) Fujita, M. Chem. Soc. Rev. 1998, 27, 417-425.

(4) Swiegers, G. F.; Malefetse, T. J. Chem. Rev. 2000, 100, 3539-3539.

(5) Chakrabarty, R.; Mukherjee, P. S.; Stang, P. J. Chem. Rev. 2011, 111, 6810-6918.

(6) Long, J. R.; Yaghi, O. M. Chem. Soc. Rev. 2009, 38, 1213-1214.

(7) Murray, L. J.; Dinca, M.; Long, J. R. Chem. Soc. Rev. 2009, 38, 1294-1314.

(8) Sumida, K.; Rogow, D. L.; Mason, J. A.; McDonald, T. M.; Bloch, E. D.; Herm, Z. R.; Bae, T.-H.; Long, J. R. Chem. Rev. 2012, 112, 724-781. 
(9) Allendorf, M. D.; Bauer, C. A.; Bhakta, R. K.; Houk, R. J. T. Chem. Soc. Rev. 2009, 38, 1330-1352.

(10) Cui, Y.; Yue, Y.; Qian, G.; Chen, B. Chem. Rev. 2012, 112, 1126-1162.

(11) Zhang, W.; Xiong, R.-G. Chem. Rev. 2012, 112, 1163-1195.

(12) Kurmoo, M. Chem. Soc. Rev. 2009, 38, 1353-1379.

(13) Coffman, R. E.; Buettner, G. R. J. Phys. Chem. 1979, 83, 2387-2392.

(14) Pardo, E.; Carrasco, R.; Ruiz-Garcia, R.; Julve, M.; Lloret, F.; Munoz, M. C.; Journaux, Y.; Ruiz, E.; Cano, J. J. Am. Chem. Soc. 2008, 130, 576-585.

(15) Fernandez, I.; Ruiz, R.; Faus, J.; Julve, M.; Lloret, F.; Cano, J.; Ottenwaelder, X.; Journaux, Y.; Munoz, M. C. Angew. Chem. Int. Ed. 2001, 40, 3039-3042.

(16) Dul, M. C.; Pardo, E.; Lescouezec, R.; Chamoreau, L. M.; Villain, F.; Journaux, Y.; Ruiz-Garcia, R.; Cano, J.; Julve, M.; Lloret, F.; Pasan, J.; Ruiz-Perez, C. J. Am. Chem. Soc. 2009, 131, 14614-14615.

(17) Pardo, E.; Ferrando-Soria, J.; Dul, M.-C.; Lescouëzec, R.; Journaux, Y.; Ruiz-García, R.; Cano, J.; Julve, M.; Lloret, F.; Cañadillas-Delgado, L.; Pasán, J.; Ruiz-Pérez, C. Chem. Eur. J. 2010, 16, 12838-12851.

(18) Dul, M. C.; Ottenwaelder, X.; Pardo, E.; Lescouezec, R.; Journaux, Y.; Chamoreau, L. M.; Ruiz-Garcia, R.; Cano, J.; Julve, M.; Lloret, F. Inorg. Chem. 2009, 48, 5244-5249.

(19) Pereira, C. L. M.; Pedroso, E. F.; Stumpf, H. O.; Novak, M. A.; Ricard, L.; Ruiz Garcia, R.; Riviere, E.; Journaux, Y. Angew. Chem. Int. Ed. 2004, 43, 955-958.

(20) Pardo, E.; Cangussu, D.; Dul, M.-C.; Lescouezec, R.; Herson, P.; Journaux, Y.; Pedroso, E. F.; Pereira, C. L. M.; Muñoz, M. C.; Ruiz-Garcia, R.; Cano, J.; Amorós, P.; Julve, M.; Lloret, F. Angew. Chem. Int. Ed. 2008, 47, $4211-4216$.

(21) Ferrando-Soria, J.; Ruiz-Garcia, R.; Cano, J.; Stiriba, S. E.; Vallejo, J.; Castro, I.; Julve, M.; Lloret, F.; Amoros, P.; Pasan, J.; Ruiz-Perez, C.; Journaux, Y.; Pardo, E. Chem.-Eur. J. 2012, 18, 1608-1617.

(22) Laudise, R. A. Chem. Eng. News 1987, 65, 30-43.

(23) Rabenau, A. Angew. Chem. Int. Ed. 1985, 24, 1026-1040.

(24) Ferey, G. Chem. Mater. 2001, 13, 3084-3098.

(25) Rosi, N. L.; Eddaoudi, M.; Kim, J.; O'Keeffe, M.; Yaghi, O. M. CrystEngComm 2002, 401-404.

(26) Rebecca H. Laye and Eric J. L. Mclnnes, Eur. J. Inorg. Chem., 2004, 2004, 2811-2818.

(27) Cervera, B.; Sanz, J. L.; Ibanez, M. J.; Vila, G.; LLoret, F.; Julve, M.; Ruiz, R.; Ottenwaelder, X.; Aukauloo, A.; Poussereau, S.; Journaux, Y.; Munoz, M. C. J. Chem. Soc., Dalton Trans. 1998, 781-790.

(28) a) BrukerAXS Inc, Madison, Wisconsin, USA, 1998; b) Sheldrick, G. M. Acta Cryst. 2008 A64, 112; c) Blessing, R. H. Acta Cryst. 1995, A51, 33

(29) Blay, G.; Fernández, I.; Pedro, José R.; Ruiz-García, R.; Muñoz, M. C.; Cano, J.; Carrasco, R. Eur. J. Org. Chem. 2003, 1627-1630.

(30) Padilla-Martinez, II; Chaparro-Huerta, M.; Martinez-Martinez, F. J.; Hopfl, H.; Garcia-Baez, E. V. Acta Cryst. 2003, E59, O825-O827.

(31) Tamaki, H.; Zhong, Z. J.; Matsumoto, N.; Kida, S.; Koikawa, M.; Achiwa, N.; Okawa, H. J. Am. Chem. Soc. 1992, 114, 6974-6979.

(32) Decurtins, S. Inorg. Chim. Acta 1994, 216, 65.

(33) Gruselle, M.; Train, C.; Boubekeur, K.; Gredin, P.; Ovanesyan, N. Coord. Chem. Rev. 2006, 250, $2491-2500$.

(34) O'Keeffe, M.; Peskov, M. A.; Ramsden, S. J.; Yaghi, O. M. Acc. Chem. Res. 2008, 41, 1782-1789.

(35) Lloret, F.; Julve, M.; Cano, J.; Ruiz-Garcla, R.; Pardo, E. Inorg. Chim. Acta 2008, 361, 3432-3445. 
(36) Pardo, E.; Morales Osorio, I.; Julve, M.; Lloret, F.; Cano, J.; Ruiz Garcia, R.; Pasan, J.; Ruiz Perez, C.; Ottenwaelder, X.; Journaux, Y. Inorg. Chem. 2004, 43, 7594-7596.

(37) Pardo, E.; Ruiz-Garcia, R.; Cano, J.; Ottenwaelder, X.; Lescouezec, R.; Journaux, Y.; Lloret, F.; Julve, M. Dalton Trans. 2008, 2780-2805.

(38) Aakeroy, C. B.; Hughes, D. P.; Nieuwenhuyzen, M. J. Am. Chem. Soc. 1996, 118, 10134-10140.

(39) Burrows, A. D.; Chan, C.-W.; Chowdhry, M. M.; McGrady, J. E.; Mingos, D. M. P. Chem. Soc. Rev. $1995,24$.

(40) Tadokoro, M.; Nakasuji, K. Coord. Chem. Rev. 2000, 198, 205-218.

(41) Brammer, L. Chem. Soc. Rev. 2004, 33, 476-489.

(42) Tadokoro, M.; Isobe, K.; Uekusa, H.; Ohashi, Y.; Toyoda, J.; Tashiro, K.; Nakasuji, K. Angew. Chem. Int. Ed. $1999,38,95-98$.

(43) Öhrström, L.; Larsson, K.; Borg, S.; Norberg, S. T. Chem. Eur. J. 2001, 7, 4805-4810.

(44) Tadokoro, M.; Shiomi, T.; Isobe, K.; Nakasuji, K. Inorg. Chem. 2001, 40, 5476-5478.

(45) Larsson, K.; Ohrstrom, L. CrystEngComm 2003, 5, 222-225.

(46) Tadokoro, M.; Kanno, H.; Kitajima, T.; Shimada-Umemoto, H.; Nakanishi, N.; Isobe, K.; Nakasuji, K. PNAS 2002, $99,4950-4955$.

(47) Wells, A. F. Acta Cryst. 1954, 7, 535-544.

(48) Ohrstrom, L.; Larsson, K. Dalton Trans. 2004, 347-353.

(49) Buser, H. J.; Schwarzenbach, D.; Petter, W.; Ludi, A. Inorg. Chem. 1977, 16, 2704-2710.

(50) Witzel, M.; Babel, D. Acta Cryst. 1984, A40, C216-C216.

(51) Wells, A. F. Acta Cryst. 1954, 7, 545-554.

(52) Wells, A. F. Structural Inorganic Chemistry; Clarendon Press: Oxford, 1984.

(53) Li, H.; Eddaoudi, M.; O'Keeffe, M.; Yaghi, O. M. Nature 1999, 402, 276.

(54) Férey, G.; Mellot-Draznieks, C.; Serre, C.; Millange, F.; Dutour, J.; Surblé, S.; Margiolaki, I. Science 2005, 309, 2040-2042. 
Supplementary information for:

Solvothermal synthesis of oxamate-based helicate: temperature dependence of the hydrogen bond structuring in the solid.

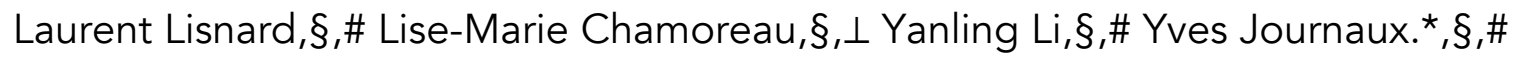

$\S$. Institut Parisien de Chimie Moléculaire, UPMC Univ Paris 06, Paris, 75005, France.

\#. CNRS, Institut Parisien de Chimie Moléculaire, UMR 7201, Paris, 75005, France.

$\perp$. Centre de résolution structurale, Institut Parisien de Chimie Moléculaire, Paris, 75005, France. 


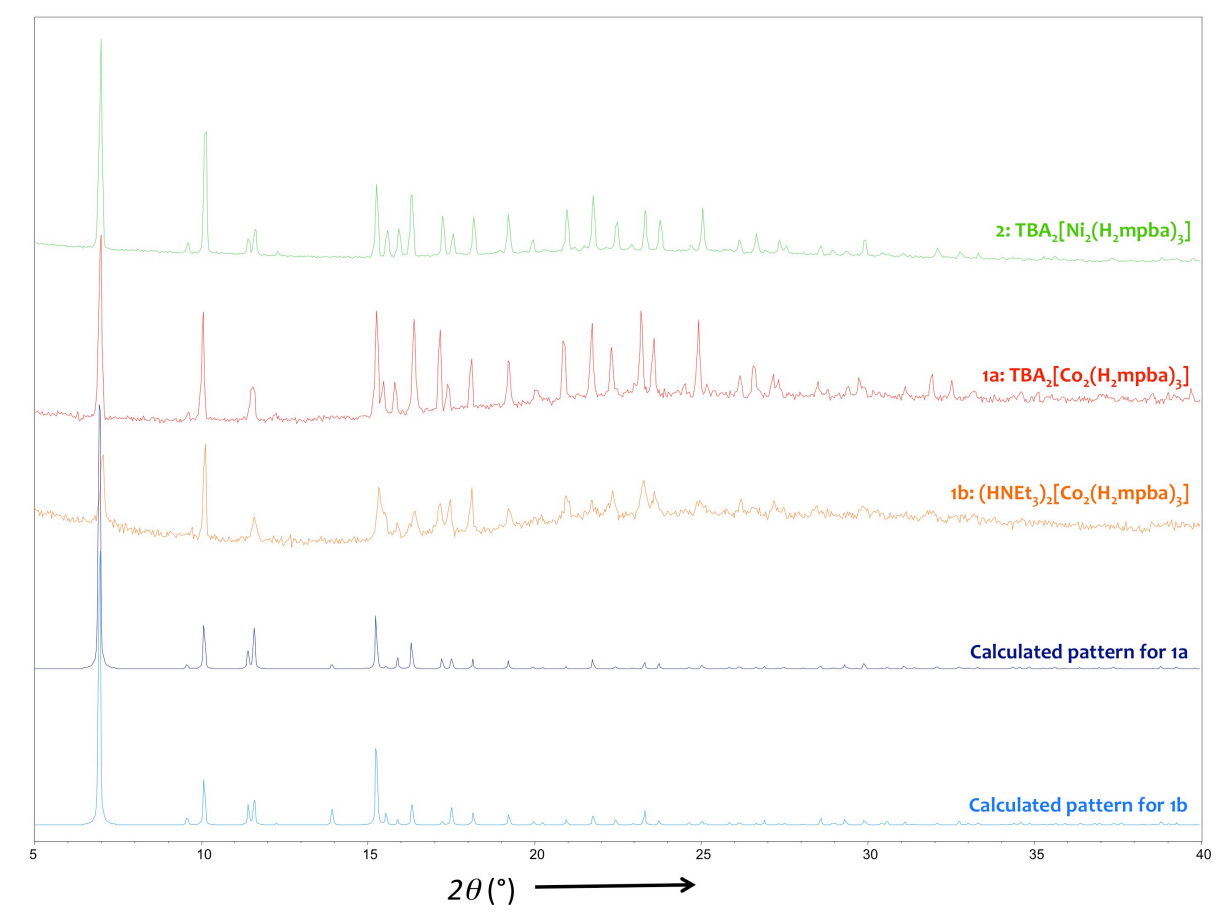

Figure S1: Experimental X-ray powder diffraction patterns for $1 \mathrm{a}, 1 \mathrm{~b}$ and 2 and calculated patterns for $1 \mathrm{a}$ and $1 \mathrm{~b}$.

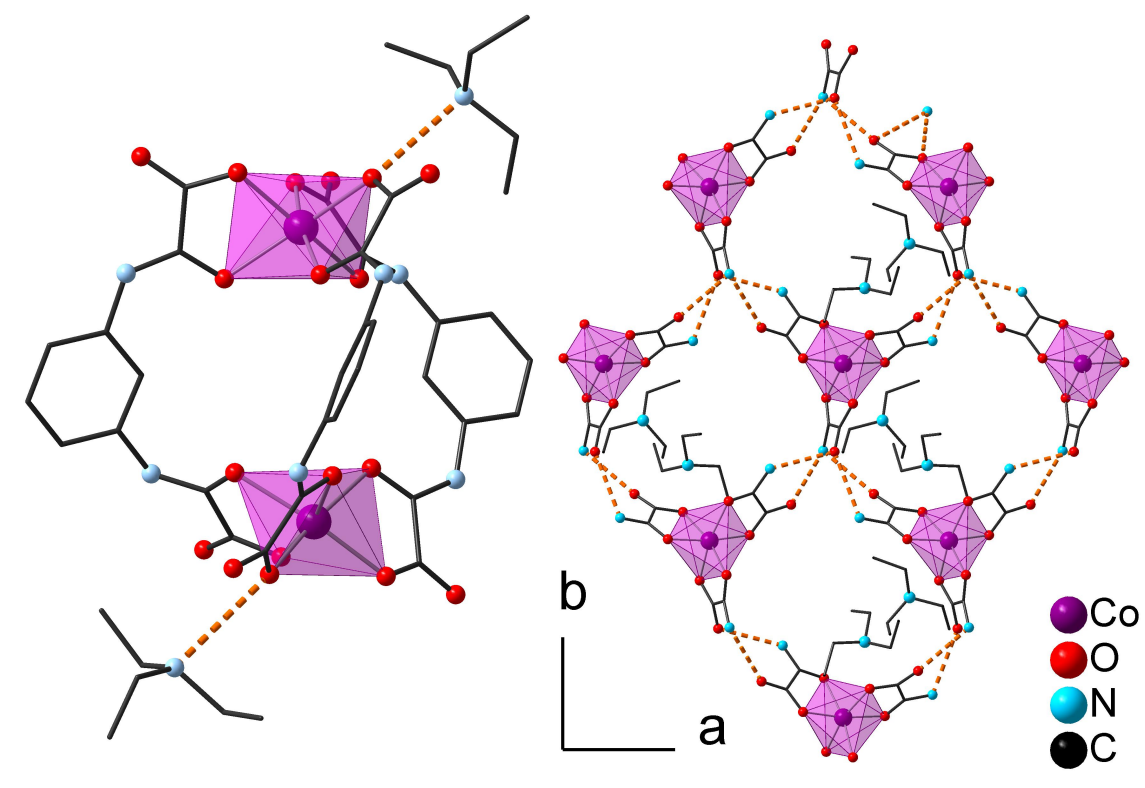

Figure S2: Left: representation of the $\mathrm{N}-\mathrm{H} \cdots \mathrm{O}$ bond (orange dotted lines) between the bimetallic complex and its $\mathrm{HNEt}_{3}{ }^{+}$counter-ions; right: crystal packing of 3 in the (ab) plane including the counter-ions. 


\section{SYNOPSIS TOC}

Solvothermal synthesis has been successfully tested as a new synthetic method towards oxamate-based coordination compounds. Novel bimetallic helicate complexes have been obtained with divalent metal ions and benzenedioxamic acid. Crystallographic studies have also shown a temperature-dependent $\mathrm{H}$-bond networking that leads to hetero or homochiral 3D architectures.

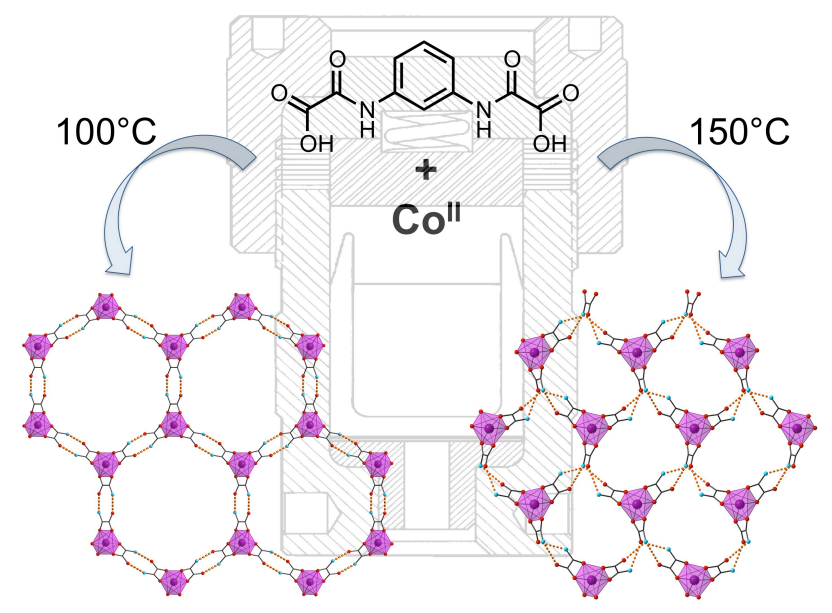

